\title{
The Macro Financing of Natural Hazards in Developing Countries
}

\author{
Olivier Mahul and Eugene Gurenko \\ Financial Markets for Social Safety Net \\ Financial and Private Sector Department \\ The World Bank
}

\begin{abstract}
:
Mahul and Gurenko propose a financial model to address the design of efficient risk financing strategies against natural disasters at the country level. It is simple enough to shed analytical light on some of the key issues but flexible and realistic enough to provide some quantitative guidance on the ex ante financing of catastrophic losses. The risk financing problem is decomposed into two steps. First, the resource gap, defined as the difference between losses and available ex-post resources (e.g., post-disaster aid), is identified. It determines the losses to be financed by ex ante financial instruments (reserves, catastrophe insurance and contingent debt). Second, the cost-minimizing financial arrangements are derived from the marginal costs of the financial instruments. The model is solved through a series of graphical analyses that make this complex financial problem easier to apprehend. This model captures and explains the main impacts of financial parameters (e.g., insurance premium, cost of capital) on efficient risk financing structures.
\end{abstract}

\section{World Bank Policy Research Working Paper 4075, December 2006}

The Policy Research Working Paper Series disseminates the findings of work in progress to encourage the exchange of ideas about development issues. An objective of the series is to get the findings out quickly, even if the presentations are less than fully polished. The papers carry the names of the authors and should be cited accordingly. The findings, interpretations, and conclusions expressed in this paper are entirely those of the authors. They do not necessarily represent the view of the World Bank, its Executive Directors, or the countries they represent. Policy Research Working Papers are available online at http://econ.worldbank.org. 


\section{Introduction}

The thesis underlying the Bank's work on catastrophe risk management is that the reduction of vulnerability of the poor is an important part of development and poverty alleviation. "Reducing disaster vulnerability in developing countries may very well be the most critical challenge facing development in the new millennium...it is an issue of doing development right, and making sure that activities contribute to reducing disasters rather than exacerbating them." "This argument of reducing the growing vulnerability of developing countries to natural disasters is indeed the best argument for ex-ante risk management at the country level. Natural disasters generate disproportionately large human and economic losses. In the absence of well functioning insurance markets, most of the economic loss from natural and man-made disasters is borne by governments and households. Unfortunately, extremely low insurance penetration is a widely spread reality in the World Bank's client countries, ranging between 0.3 to 1 percent, which to a large extent explains why the world's poor suffer disproportionately from natural disasters.

There is growing evidence that the frequency and severity of natural disasters is on the rise. As a result of the increasing concentration of population in disaster prone metro areas, substandard construction practices and low insurance penetration, the fiscal and economic risk exposure of developing countries to catastrophic events looms large, and in the absence of active risk management, is becoming larger by the year. For example, floods in Poland in 1998 caused a 3 percent loss in GDP, the Marmara 1999 earthquake in Turkey in 1999 generated a 5 percent loss in GDP, and Honduras faced a 20 percent loss in GDP following the hurricane Mitch in 1998.

Although the low rate of insurance penetration in developing countries to a large extent can be attributed to their level of wealth, when it comes to catastrophe risk coverage this correlation between insurance penetration and the country' GDP can be successfully defied as has been shown by the recent example of Turkey, which only in 3 years has managed to raise insurance penetration for residential catastrophe insurance coverage from 3 to 17 percent. Historically, however, most governments have not taken much interest in hedging against disasters (until after the fact of a major event occurring) because of low perceived vulnerability levels and the fact that most severe natural hazards manifest themselves only infrequently. In addition, there has been a willingness on the part of rich countries and other donors to provide post disaster funding for vulnerable countries subject to frequent catastrophic events. The World Bank alone has provided more than $\$ 38$ billion of post disaster funding over the last twenty years. The availability of free or inexpensive post-disaster funding discourages proactive ex ante risk management on the part of disaster prone countries, such as looking into market driven risk transfer solutions, including reinsurance. Indeed, given the cost of risk financing solutions offered by the private markets, it is rational for the developing countries to rely largely on free ex post aid and development banks' post-emergency lending. Other reasons for the low insurance penetration rate are the underdeveloped state of domestic insurance markets, which lack the capital base, low underwriting expertise, a common mistrust in the formal insurance sector by consumers, and weak regulatory capacity.

\footnotetext{
${ }^{1}$ James Wolfensohn, former President of the World Bank Group, 2003.
} 
By ensuring that sufficient liquidity exists very soon after a disaster, modern funding approaches can help to speed recovery, ensure the scarce government funds are well used and reduce the risk-enhancing effects of moral hazard. In addition, catastrophe risk management can assist countries in the optimal allocation of risk in the economy, which may result in a higher economic growth, better mitigation and more effective poverty alleviation.

The approach advocated in this paper is to develop risk funding solutions that would provide countries with strong economic incentives to engage in active risk management and thus overtime achieve significant reduction in their growing vulnerability and exposures. Such a major turnaround however would require linking, at least to some extent, donors' post-disaster reconstruction grants and emergency loans from major development banks to progress achieved by countries in ex-ante catastrophe risk management. This approach also rests on the notion of leveraging the Bank's emergency funding with that of international reinsurance and capital markets. Only by combining the funding capacity of donor countries, development banks and global reinsurance and capital markets, would developing countries be in the position to adequately meet their demands for capital to fund the residual risk following major catastrophe events.

This paper maintains that when it comes to funding natural disasters ex post financing is not the right approach. Instead it proposes a formal country risk financing framework that would provide tangible incentives for proactive country risk management and promote market risk financing. A new generation of financial instruments that can address effectively these development issues is discussed. Caballero (2003) investigates the desirable features of insurance and hedging instruments countries could use to efficiently manage exogenous shocks. However, he notices that "even in the best managed emerging economies, aggregate risk management is being done with stone-aged instruments and methods” (p.37). Freeman, Keen and Mani (2003) discuss risk management options in dealing with natural disasters and discuss the role of the governments and the international community in the management of catastrophic events. Gurenko and Lester (2004) outline an ex ante risk management framework for rapid onset disasters, including risk assessment, mitigation measures and the role of ex post and ex ante risk financing techniques. They describe the range of ex ante risk financing strategies -including catastrophe insurance pools, reserve funds and contingent credit facilities- that can be used to finance the resource gap defined as the difference between potential losses and available ex post resources.

Based on the country risk financing framework proposed by Gurenko and Lester (2004), this paper further investigates efficient combinations of ex ante instruments in the financing of natural disasters. It attempts to build a model that captures the main drivers of efficient risk financing arrangements. Using graphical analyses, it illustrates the tradeoffs involved in devising efficient risk financing structures. It first identifies the resource gap in terms of frequency of occurrence. It assumes that frequent loss events are self-retained by a country as long as they do not affect its long-term development projects, while very infrequent events are funded by ex post disaster relief programs from the international donors and/or debt forgiveness programs from the development banks. The remaining "in-between" risks define the resource gap to be funded by ex ante risk 
financing instruments (i.e., insurance, contingent credit and reserves). This gap is divided into multiple layers of risk. The marginal costs of the instruments (i.e., insurance premium, cost of internal and external capital) are then compared within each of these layers to determine efficient risk financing strategies. Numerical examples illustrate the tradeoff between the financial instruments.

The structure of the paper is as follows. Section 2 briefly discusses the vulnerability of developing countries to natural disasters. Section 3 explains the main limitations of post-disaster funding. Section 5 presents the conceptual model for the financing of catastrophic risks. Section 6 concludes.

\section{Vulnerability of Developing Countries to Natural Disasters}

There is a growing evidence that the coming years will see a rise in both the frequency and severity of natural disasters. The number of extreme weather events (e.g., floods, hurricanes, windstorms and droughts) increased from 20 during the 1950's to 89 during the 1990's (Munich Re 2001). The increased frequency of natural disasters coincides with the increasing concentration of population and assets in disaster prone metro areas which leads to growing economic losses. According to Munich Re's estimates, in the 1990's, economic losses from extreme weather related events world-wide increased to US $\$ 630$ billion from US $\$ 41$ billion in the 1950's (in 2000 prices). In 2003 alone, natural catastrophes claimed nearly 60,000 lives and caused about US\$70 billion in economic losses (Swiss Re 2004).

As a result of the increased concentration of the world's population in vulnerable urban areas, substandard construction practices and low insurance penetration (see below), the fiscal and economic risk exposure of developing countries to catastrophic events looms large. As illustrated in Figure 1, average damages from large disasters faced by developing countries on average amount to 7.1\% of GDP over the period 1977-2001, with a peak at $12.3 \%$ of GDP in 1987-1991. Such considerable risk exposures to natural disasters affect most small states, where these averages are much higher - 9\% over 19972001 and 34.7\% over 1987-1991.

\section{Figure 1. Average Damages from Large disasters}

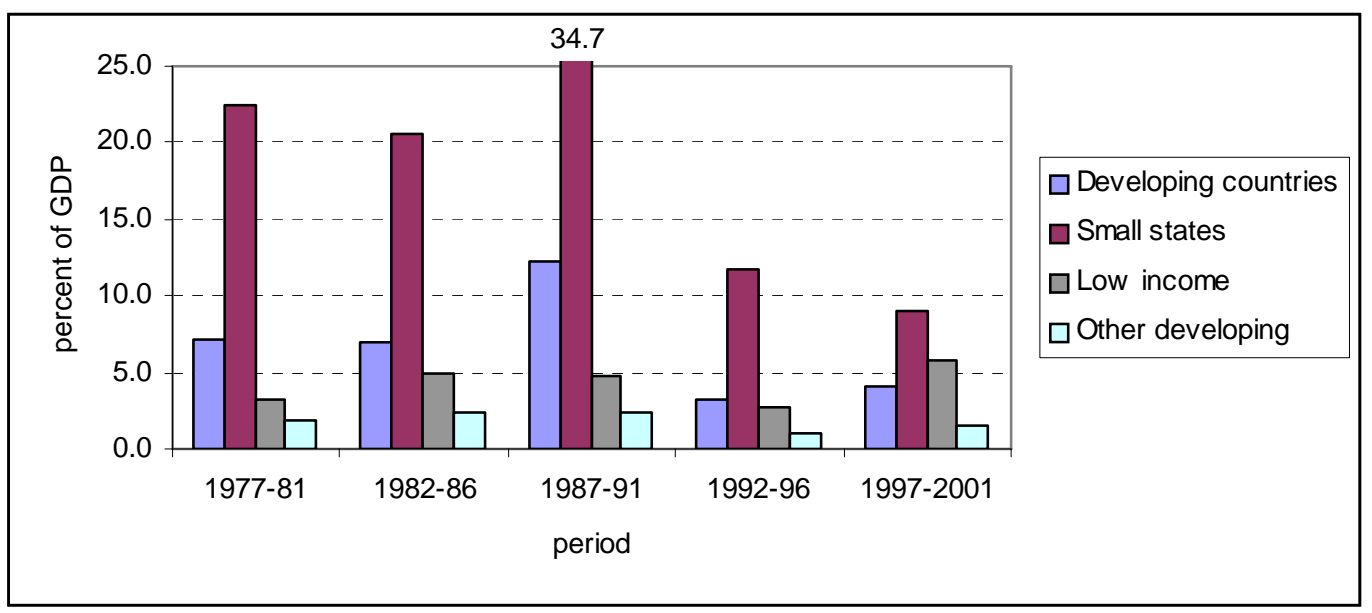


Source: World Bank 2003.

At the country level, natural disasters can have numerous adverse social, developmental, economic and fiscal impacts. Among those are: the worsening the fiscal position, as the spending needs rise; the weakening of trade balance, as the country's export capacity falls and reconstruction needs increase demand for imported goods and materials. This in turn is likely to put downward pressure on the exchange rate for local currency, reflecting both the weakening trade balance and reversal in private capital flows due to the shaken confidence of foreign investors, and give rise to inflation (Freeman, Keen and Mani 2003). ${ }^{2}$

As a consequence of limited insurance coverage for catastrophic risks provided by the local market and the lack of risk awareness or economic incentives to engage in ex ante risk management, governments in developing countries generally rely on domestic budget, including diversion of resources from other projects, and on extensive financing from international donors to absorb the losses caused by natural disasters.

Table 1 shows the gap between developed and developing countries in terms of insurance coverage for natural disasters. Only 5\% of the US $\$ 22$ billion losses caused by an earthquake were covered by insurance in Turkey in 1999, compared with $47 \%$ of losses insured in the case of Northridge quake in the US and 100\% of losses insured in the case of winter storms in France.

Table 1. Economic and insured losses from major natural disasters.

\begin{tabular}{llcc}
\hline \multicolumn{1}{c}{ Event (year) } & \multicolumn{1}{c}{ Country } & $\begin{array}{c}\text { Economic losses } \\
\text { (US\$ billion) }\end{array}$ & $\begin{array}{c}\text { Insured losses } \\
\text { (as a percent of } \\
\text { economic losses) }\end{array}$ \\
\hline Earthquake (1999) & Izmit Turkey & 22.0 & $5 \%$ \\
Hurricane (1999) & Honduras & 3.0 & $6 \%$ \\
Floods (1997) & Poland & 3.5 & $6 \%$ \\
Earthquake (2001) & Gujarat/Bhuj, India & 0.6 & $2 \%$ \\
Earthquake (1992) & Northridge, USA & 43.0 & $47 \%$ \\
Winter storm (1999) & France & 6.2 & $100 \%$ \\
\hline
\end{tabular}

Sources: Gurenko (2004), Swiss Re (2002), IIASA (1999).

The impact of natural disasters on the economic growth and the domestic budget is illustrated in Table 2. Although the US Northridge quake caused US\$43 billion losses, its impact was almost negligible on the US economic growth $(0.3 \%)$ and limited on the government revenues (2\%). On the contrary, in countries where these infrequent shocks cannot be absorbed by the insurance industry and thus are borne by the country itself the

\footnotetext{
${ }^{2}$ The above mentioned deterioration in the current account balance however can be somewhat offset by the inflow of foreign donor aid and payments by foreign reinsurers under reinsurance contracts with the local insurance market.
} 
adverse economic and social impact of natural disasters can be simply devastating. Hurricane Mitch in Honduras in 1998, for instance, destroyed 34\% of national GDP and was equivalent to $158 \%$ of total government annual revenue. Even for large national economies, the fiscal implications of natural disasters can be quite significant. The Gujarat earthquake, for instance, had a rather small impact on the overall Indian economy, around $1 \%$ of GDP, but the fiscal impact was considerably larger, amounting to $7 \%$ of government revenues.

Table 2. Uninsured economic loss from some recent natural disasters

\begin{tabular}{|c|c|c|c|}
\hline \multirow[b]{2}{*}{ Event (year) } & \multirow[b]{2}{*}{ Country } & \multicolumn{2}{|r|}{ Loss } \\
\hline & & $\begin{array}{l}\text { Percent of } \\
\text { GDP }\end{array}$ & $\begin{array}{l}\text { Percent of government } \\
\text { revenues }\end{array}$ \\
\hline Earthquake (1992) & Northridge, USA & $0.3 \%$ & $2 \%$ \\
\hline Earthquake (2001) & Gujarat/Bhuj, India & $1 \%$ & $7 \%$ \\
\hline Floods (1997) & Poland & $3 \%$ & $11 \%$ \\
\hline Earthquake (1999) & Armenia, Colombia & $3 \%$ & $23 \%$ \\
\hline Earthquake (1985) & Mexico City, Mexico & $4 \%$ & $26 \%$ \\
\hline Earthquake (1999) & Izmir, Turkey & $5 \%$ & $21 \%$ \\
\hline Floods (1998) & Bangladesh & $17 \%$ & $152 \%$ \\
\hline Earthquake (1986) & El Salvador, San Salvador & $27 \%$ & $180 \%$ \\
\hline Hurricane (1998) & Honduras & $34 \%$ & $158 \%$ \\
\hline
\end{tabular}

Source: Gurenko (2004).

Beyond the immediate adverse macroeconomic impacts of disasters, the indirect longterm consequences of natural disasters may be even more severe. The fiscal impact of Gujarat/Bhuj quake forced the Indian government to increase its fiscal deficit by a few percentage for several subsequent years (Gurenko 2004). Hurricane Mitch in Honduras caused a stagnation of national GDP for several years despite the original pre-event projections of highly positive economic growth. Natural disasters are also likely to worsen the economic fundamentals of key industries in the affected developing countries. The increasing post event government borrowings to absorb the financial consequences of a disaster are likely to coincide with a decline in government tax revenues due to the fall in both GDP and export earning capacity of key industries which in turn may trigger downgrades of sovereign debt ratings due to the worsened public sector debt service ratios.

Following major natural catastrophes, the ability of an affected country to have immediate access to ample liquidity has critical implications for the ultimate size of indirect economic losses generated by the destruction of physical assets. Prompt funding of post-loss projects is likely to speed the recovery of the economy and consequently, 
would reduce the need to borrow in order to meet the fiscal shortfall. ${ }^{3}$ The traditional ex post funding approach usually precludes funds from being disbursed promptly in the aftermath of a natural disaster.

\section{Ex Post Funding Approach: What Is Wrong?}

Historically, most governments have not taken much interest in ex ante management of disasters because of low perceived vulnerability levels and the fact that most severe hazards manifest themselves very infrequently (Kaplow 1991, Kunreuther 1996). In addition to this cognitive failure, there has been a willingness on the part of the international community to provide post disaster funding for vulnerable countries exposed to catastrophic events. The World Bank alone has disbursed US\$38.3 billion of emergency and reconstruction loans (ERL) over the last twenty years, as shown on Figure 2. Almost 23 percent of these ERL were provided to Latin American and Caribbean countries and more than 18 percent to African countries.

\section{Figure 2. World Bank emergency lending, 1980-2003}

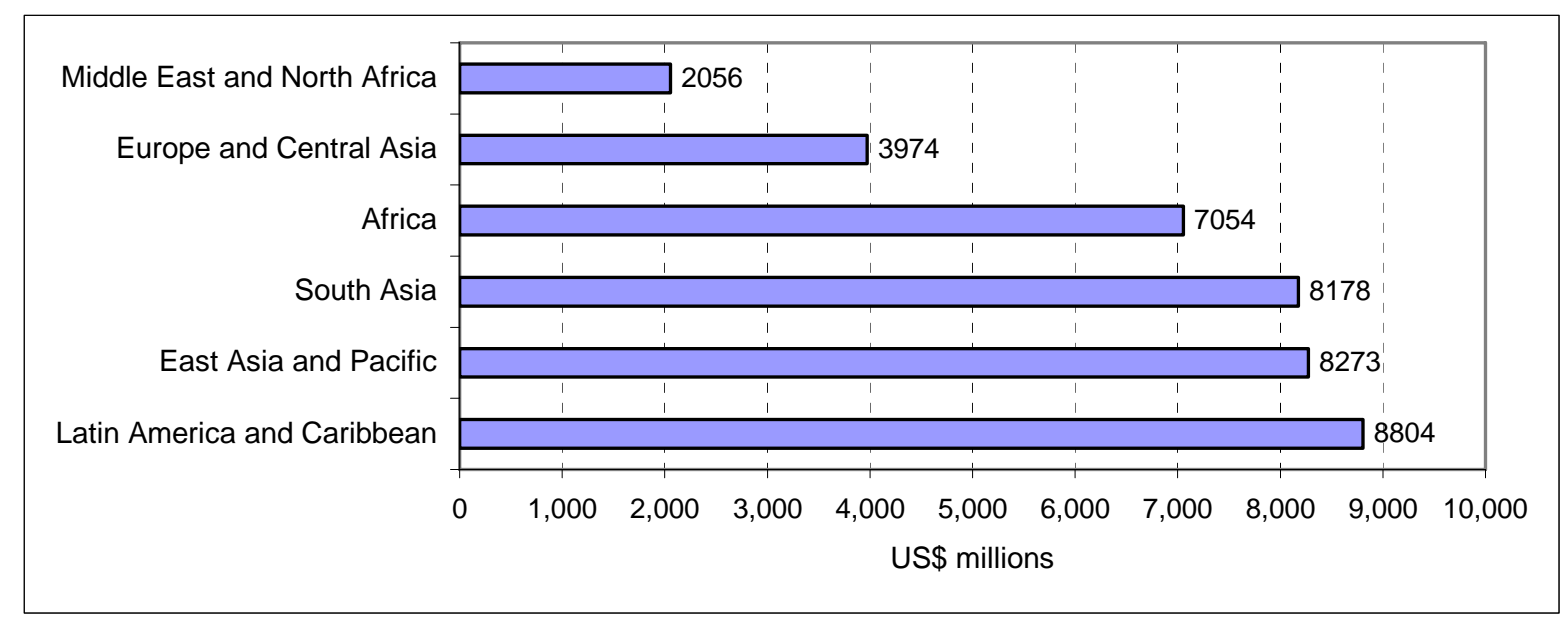

Source: World Bank (2003).

The availability of free or inexpensive post-disaster donor funding discourages proactive ex ante risk management on the part of disaster prone countries, such as looking into market driven risk transfer solutions, including reinsurance. Indeed, given the cost of risk financing solutions offered by the private markets, it is rational for the developing countries to rely largely on inexpensive ex post aid and development banks' postemergency lending. This poses a “Samaritan’s dilemma” (Coate 1995).

As a consequence of underdeveloped domestic insurance markets and the lack of risk awareness or economic incentives to engage in ex ante risk management, governments generally adopt reactive response approaches to natural disasters, relying on domestic

\footnotetext{
${ }^{3}$ Post-loss funding should not be used to replace lost assets, but to invest in post-loss projects that create the highest social and economic value (Clarke and Doherty 2004).
} 
budgets, including diversion of resources from other projects, and on extensive financing from international donors. In fact, emergency funding for reconstruction from international donors has become a linchpin of some governments' strategies for funding disaster reconstruction which is often supplemented by emergency reconstruction lending programs from the World Bank and other multilateral development banks. In addition, it is usually hard for the donor community to credibly enforce its pledge to reduce its ex post assistance if ex ante mitigation measures have not been implemented because of the overriding humanitarian considerations once a disaster occurs.

This does not mean however that ex post disaster funding from donors and international development banks cannot play an important role in the country's risk management strategy, but that over-reliance on this approach has major limitations in terms of efficiency, effectiveness, and sufficiency.

Ex post funding approaches are inefficient. The lack of advance planning and resource allocation prevents funds from being immediately available after a disaster. Multilateral assistance can take a long time to disburse. As a result, the adverse social and developmental impacts of disrupted economic activity are far greater due to the delayed response.

Ex post funding approaches are ineffective. Resource allocation after a disaster may be ad hoc. Resources may be targeted on bureaucratic or political considerations, rather than directed to those expenditures and investments that are most likely to restore economic activity promptly. The diversion of limited fiscal resources away from development projects, creating high economic and social value added, to politically motivated low net return purposes, such as middle class housing, can have considerable opportunity costs and long term adverse economic effects.

Ex post funding approaches are insufficient. Most developing countries face ongoing fiscal constraints. The quantity of funds available for relief and reconstruction may be far off from what is needed, even with additional borrowing and grants from the donor community. This leaves a substantial resource gap.

A fundamentally consequence of natural disasters is that they tend to have the greatest impact on the poor, who are affected most by these adverse events. Scarce multilateral resources, which could have been utilized for growth and poverty reduction goals, are thus diverted by catastrophes, or more precisely, by the lack of appropriate ex ante disaster risk financing strategies.

\section{A Formal Country Risk Financing Approach}

By ensuring that sufficient liquidity exists very soon after a disaster, modern funding approaches can help to speed recovery, ensure the scare government funds are well used and reduce the risk of moral hazard. In addition, catastrophe risk management can assist countries in the optimal allocation of risk in the economy, which may result in higher growth, better mitigation, and more effective poverty alleviation.

The approach advocated in this paper is to develop risk funding solutions that would provide countries with strong incentives to engage in active risk management and thus 
overtime achieve significant reduction in their growing vulnerability and risk exposures. Such a major turnaround however would require linking, at least to some extent, donors' post-disaster reconstruction grants and emergency loans from major development banks to progress achieved by countries in ex-ante catastrophe risk management. This approach also rests on the notion of leveraging the Bank's emergency funding with that of international reinsurance and capital markets. Only by combining the funding capacity of donor countries, development banks and global reinsurance and capital markets, would developing countries be in the position to adequately meet their demands for risk capital to fund economic losses inflicted by natural disasters.

In the larger industrial countries, losses from natural disasters are typically funded through a combination of private risk financing arrangements and an efficient public revenue system relying on wide and deep taxation catchments (Lewis and Murdoch 1996, Priest 1996). In the case of developing countries, which have relatively low tax ratios and ongoing fiscal pressures, funding sources for post disaster reconstruction tend to be more varied, with a strong emphasis on assistance from international donors. Multilaterally sourced infrastructure loans and relief aid from donors agencies are among the most common sources of such disaster funding.

A number of developing countries exposed to natural disasters has a limited capacity to absorb economic shocks caused by such disasters, thus relying on external sources of funding. Due to agency and information problems, new external capital is usually more expensive than internal capital (Froot, Scharfstein and Stein 1993, Doherty 2000). These friction costs make the country risk averse to catastrophic events and thus make risk management strategies valuable. ${ }^{4}$ The World Bank has been developing a country risk management model which is partly based on corporate risk management principles but also factors in key economic and social metrics such as government fiscal profiles, the living conditions of the poor, and investment in risk mitigation (Gurenko and Lester 2003). This risk management approach at the country level relies on the assessment of the country fiscal exposure when all the cost-effective risk mitigation measures have been implemented, the identification of potential funding gaps between damages sustained by the country and funds available, and the financing of these gaps through private capital markets, and World Bank lending instruments.

\section{Risk assessment}

The analysis of hazard frequencies and intensities is critical to assess the country fiscal exposure to natural disasters. The methodology used by the catastrophe insurance modeling industry is based on probabilistic risk assessment models (Khater and Kuzak 2002). Such models analyze the historical loss information. However, the quantification of catastrophe risk fundamentally differs from traditional risks such as automobile or fire. First, catastrophic events are, by nature, infrequent (for the insurer) and thus the historical data are limited or even unavailable. Second, the severity of catastrophic events is high because these large-scale phenomena, such as earthquakes or floods, impact a large number of households and properties at the same time. Historical data on these low frequency, high severity events are usually insufficient to estimate future losses

\footnotetext{
${ }^{4}$ In a perfect market where external capital would not be more expensive than internal capital, i.e, in the absence of friction costs, risk management would be irrelevant.
} 
accurately. In such cases, risk assessment models offer valuable scientific guidance by anticipating credible events that could occur in the future, but have not yet taken place. These probabilistic models have been recently developed to assess the risk of rapid onset natural disasters (e.g., earthquakes, floods, hurricanes, cyclones). Using a similar approach, the World Bank Insurance Practice is working on a drought risk assessment model.

The methodology relies on simulation techniques and has the following four components: (i) hazard module, (ii) exposure module, (iii) vulnerability module and (iv) loss module.

The hazard module defines occurrence parameters of the peril and the probability of occurrence of all events likely to cause damage to assets. The relevant parameters are selected from the analysis of historical data and scientific studies available. These parameters in the case of earthquakes are location, magnitude, and depth. In the case of drought, they include intensity (measured by an appropriate drought index involving precipitation, soil moisture, etc.), duration, starting date and spatial coverage.

The exposure module defines the items at risk of loss and their average value of replacement. In the case of rapid onset natural disasters, items at risk are mainly stock items, while they are mainly flow items (e.g., agricultural crop yields) in the case of drought.

The vulnerability module quantifies the damage caused to each item at risk by the intensity of a given event at a particular location. Vulnerability is measured in terms of the damage factor, which is the ratio of the repair cost to the replacement cost. This ratio is equal to one for flow items.

The loss module estimates the losses by multiplying the damage ratio by the value at risk. This estimation is done for each item class at each location.

The probabilistic risk assessment model, build upon the four modules, provides a set of risk metrics, i.e., quantitative measurements of the potential losses with respect to the frequency of the event, such as the average annual loss or the probable maximum loss (defined as the largest likely loss from a specific catastrophic event, for a given return period.

\section{Identifying the resource gap}

The level of risk retained by the country depends on its ability to absorb this shock without affecting its ability to invest in long-term economic development projects. The ex post sources of funding include redirected budget, tax increases, diverted loans (usually involving the development banks) and increased borrowing (Gurenko and Lester 2004). The size and the availability of the country's fiscal resources can be typically approximated by the size of the fiscal surplus or the percentage of the fiscal budget that can be reallocated to address unexpected major events. The surplus of this fiscal capacity can then be used to determine the size of events in terms of probability of occurrence that can be self-financed by the government. Assume, for example, that a loss up to 8 percent of the current national budget, estimated at US\$1 billion, can be absorbed without disrupting the fiscal and macroeconomic performance and that a US\$80 million loss event has a return period of 10 years, then the government can retain losses from events 
with a probability of occurrence higher than or equal to $10 \%$. In Figure 2, this probability is denoted as $\underline{p}$ and corresponds to the amount loss $\bar{L}$.

In the event of major catastrophes, it is likely that international donors will come to the country's rescue and will provide disaster relief, either directly or by forgiving and/or rescheduling the existing sovereign debt. Although the amount and the trigger of ex post funding are unknown, we assume that it is triggered for events with frequency lower than $p$ (e.g., 1 percent or one in a hundred year events) and that it covers all losses in excess of $\bar{L}$.

The resource gap is defined as a range of losses denoted as $[\underline{L}, \bar{L}]$, or equivalently a range of return periods denoted as $[\underline{p}, \bar{p}]$, which are funded neither by self-retention because these potential losses are beyond the financial capacity of the country, nor by the international community because they are too small to attract the attention of the international community. Consequently, this gap must be funded by ex ante risk financing arrangements, as illustrated in Figure 3.

\section{Figure 3. Resource gap}

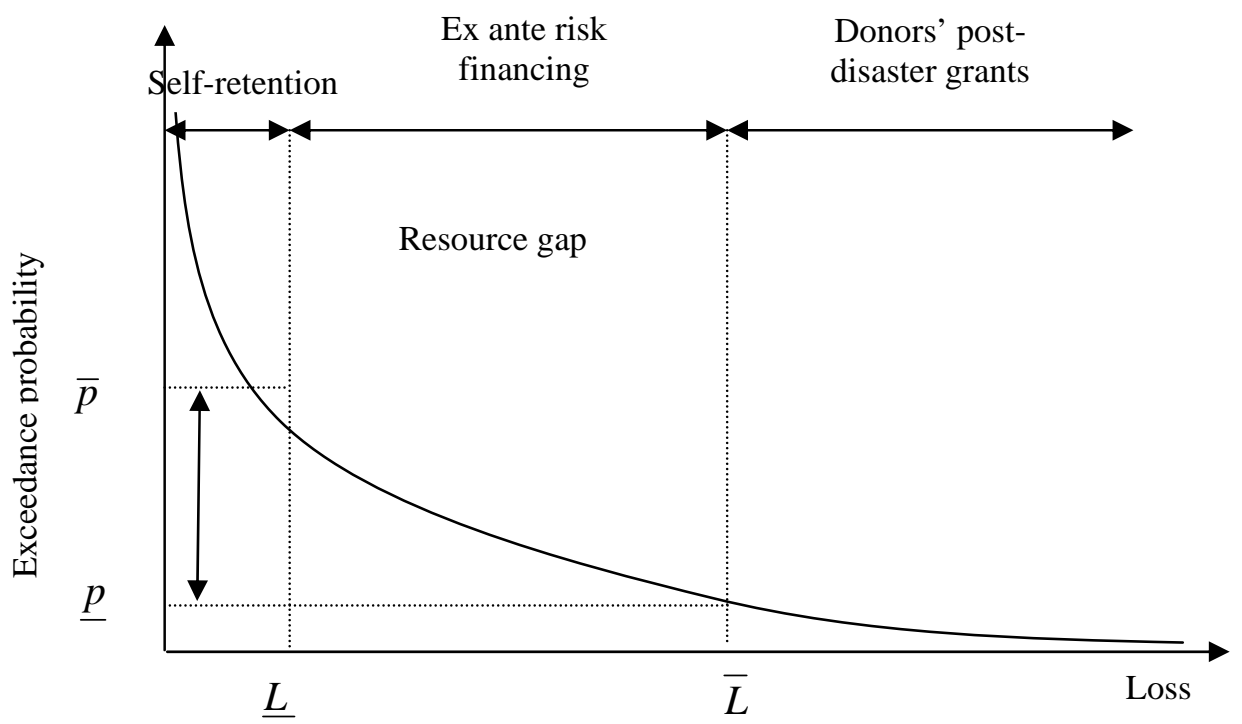

The government pays for reconstruction using different domestic sources, such as reorienting the national budget, raising taxes, new domestic credit, and the accumulation of financial reserves (Caballero 2003). However, pursuing a post-disaster financing strategy may have high opportunity costs. Budget allocations may be diverted from priority development projects in order to face emergency and recovery needs. Raising new domestic debt in an expensive post-event capital market may significantly affect the country's debt service, and raising taxes may discourage new private investments that are central to restart the economy. The government may not wish to retain all possible losses

\footnotetext{
${ }^{5}$ The appropriate balance between ex post and ex ante funding mechanisms, based on the comparison of the costs induced is not examined here and is left to further research.
} 
given the cost of risk transfer, but rather those which are below a tolerable fiscal cost threshold. This threshold should be determined with a view to avoiding disruption in the projected fiscal and macroeconomic performance and should also take into account post funding sources provided by international donors. Private risk transfer instruments can provide additional financial capacity to fund the resource gap.

\section{Financing of the resource gap}

The insurance and capital market offer several risk financing instruments to fund the resource gap.

Domestic insurance market. In many developing countries, the domestic insurance market is thin. ${ }^{6}$ Personal assets are uninsured because insurance is unavailable or expensive relative to the value of the asset, and insurers have limited access to reinsurance. In addition, recent studies of the market for catastrophic risk suggest that primary insurance companies, even in developed countries, retain large exposure to catastrophe events. Froot (2001) points out that insurers protect themselves from only a fraction of catastrophe losses through reinsurance, relying instead on self-retention. This degree of reinsurance protection is shown to be high for relatively small catastrophe losses (i.e., industry-wide insured losses from an event lower than US $\$ 1.5$ billion), but low for moderate and large catastrophe events. For example, insurance companies would reinsure only $20 \%$ of a US $\$ 6.5$ billion event, therefore retaining $80 \%$ of the losses. Several explanations for the paucity of catastrophic risk sharing have been proposed. Most of them focus on the supply side; insufficient reinsurance capital, reinsurers' market power, high frictional costs of reinsurance, information asymmetries, and other market imperfections. On the demand side, this paucity is often explained by the presence of regulatory constraints, the existence of governmental funds for disaster assistance, or some behavioral factors that do not seem to be easily justified with an utility-based approach.

Macro insurance. The transfer of catastrophic risk constitutes a key financial strategy in the economic management of disaster prone countries. The access to a new generation of macro insurance instruments to guard against the impact of natural disasters may enhance the risk financing strategy of developing countries (Caballero 2003). These macro insurance instruments should be contingent on observable variables that are independent of the country's actions, avoiding moral hazard problems, such as weather indices (e.g., rainfall, temperature). ${ }^{7}$

Catastrophe bonds. Catastrophe (cat) bonds are an example of insurance-linked securities (ILSs) that transfer catastrophic risk to the capital markets via the issue of a bond where repayment of principal is contingent upon occurrence of a predefined catastrophe. The specified value limit of the cat bond is paid out when a pre-determined indemnity level, index or parametric trigger occurs. The parametric trigger based on scientifically measurable characteristics of a hazard (e.g., wind speed, earthquake intensity) is the most frequent because it protects investors from moral hazard and provides for quick

\footnotetext{
${ }^{6}$ Non-life premiums per capita in 2002 are equal to US\$ 7.7 in Africa and US\$14.8 in South and East Asia, compared to US\$1,711.2 in North America and US\$678.2 in Western Europe (Swiss Re 2003).

${ }^{7}$ The problem of basis risk, due to the imperfect correlation between the index and the individual loss, is examined and quantified by Cummins, Lalonde and Phillips (2002, 2004).
} 
payments. Introduced in the mid 1990's, these ILSs mainly cover losses caused by wind and earthquake. Capital raised by issuing the bond is invested in safe securities such a Treasury bonds, which are held by a special-purpose vehicle (SPV). This arrangement keeps the transaction off the balance sheet of the issuer and insulates investors from the counter-party credit risk. The bond issuer holds a call option on the principal in the SPV with triggers spelled out in a bond contract. Those can be expressed in terms of issuer's losses from a pre-defined catastrophic event, by hazard characteristics, and/or its location. If the defined catastrophic event occurs, the bond-issuer can withdraw funds from the SVP to pay claims, and part or all of interest and principal payments are forgiven. If the defined catastrophic event does not occur, the investors receive their principal plus interest equal to the risk-free rate (e.g., London Inter-Bank Offered Rate (LIBOR)), plus a risk spread usually between 300 to 500 basis point over LIBOR. The average size of issue is around US\$100 million, varying from US\$10 million to almost US\$600 million. The typical maturity of cat bonds is between one year and ten years, with an average maturity of 3 years. Issuers include insurance and reinsurance companies and, in some cases, insureds. These securities offer countries an alternative to macro insurance. The cat bond market has developed slowly but steadily since it was launched in the 1990s as insurers have used the capital-market instruments as an alternative to using their own balance sheets to cover the potentially huge costs of a natural disaster, which could provoke massive insurance claims in a single area. A total of almost $\$ 13$ billion of cat bonds has been issued since the 1998s. About $\$ 8$ billion of cat bonds are outstanding, covering against natural disasters in the U.S., Western Europe, Japan, Taiwan and Australia and, more recently, Mexico.

Contingent capital. Contingent capital is an alternative risk transfer (ART) product through which capital funding is provided to the client after the occurrence of some specific risk-related loss, often on pre-loss financing terms. It is designed to provide immediate and less expensive capital to the client when it is most needed (e.g., after an economic loss) and/or most scarce (e.g., after a regional disaster). Contingent capital facilities can be viewed as put options on paid-in capital. More specifically, this is essentially a commitment by a capital provider to provide paid-in capital on pre-agreed terms if the buyer of the facility exercises that right on or before the expiration of the contingent facility (Culp, 2002). Just like a regular option, contingent capital can be characterized by the risk of underlying asset, exercise style, and strike price. While this facility can potentially provide a country with a lower cost capital relative to either a pure risk transfer solution (e.g., macro insurance) or accumulation of reserves, the major disadvantage is that once disbursed this facility could exacerbate the debt burden of the country. The effectiveness of this facility would thus depend on the country's postdisaster financial profile, and more specifically on its post-disaster ability to service debt.

Forgivable debt. Contingent debt may not be an appropriate risk financing instrument for countries with high debt burdens. An alternative risk financing strategy would be to make repayment of existing sovereign debt conditional on the occurrence of pre-defined catastrophic events. Under this approach, sovereign debt used for financing development projects would be forgiven in the event of a catastrophe. Forgivable debt can be viewed as simple debt with an embedded put option written on the catastrophe loss which allows the borrower to "put" the loss of a disaster back to the lender who has written such an option. The lender in turn is likely to protect itself from such a loss through a risk transfer 
contract to a third party. Forgiving the existing debt would enhance or restore the postloss funding capacity of a country. Such arrangements may also exist implicitly, when international financial institutions like the World Bank agree to forgive or to reschedule the existing sovereign debts following the occurrence of a disaster. However, the main advantage of explicit forgivable debt contracts is that they lay out in advance the terms and conditions under which the existing debt will be forgiven which greatly reduces the financial uncertainty in the aftermath of a disaster. Since this facility would alleviate the debt burden, the country may opt for a combination of forgivable debt and contingent debt to fund post disaster projects.

\section{Designing an Optimal Ex Ante Catastrophe Risk Financing Strategy}

The design of an ex ante risk financing strategy is a complex issue relying on advances financial engineering techniques and sophisticated simulation software. This section aims to discuss the key financial drivers in designing a financial strategy. It is based on a model that is simple enough to shed analytical light on some of the key issues but flexible and realistic enough to provide some quantitative guidance on the financing of the resource gap.

Three financial instruments are considered in this model: catastrophe insurance (or catastrophe bonds), reserves, contingent debt. They represent the main options in the ex ante financing of the resource gap. While catastrophe insurance is a risk transfer mechanism (to a third party), reserves and contingent debt are inter-temporal riskspreading mechanisms.

\section{Catastrophe insurance}

In an efficient catastrophe insurance market, where the return of shareholders equity approaches zero, the insurance premium can be decomposed as:

Premium $=$ expected loss + administrative load + catastrophe load.

Consider the insurance layer covering losses from zero and the exhaustion point $L$. The expected loss is $E \min (\tilde{l}, L)$ and the insurance premium net of the expected loss, i.e., the insurance cost, is assumed to be determined by

$$
P(L)=g(L)+d(L),
$$

where $\tilde{l}$ is the positive random loss, $g(L)$ is the cost of capital and $d(L)$ is the operating costs (including underwriting costs and loss adjustment costs). Equation (1) means that the cost of insurance is driven by the maximum possible loss $L$. The catastrophe load $g($.$) is assumed to increase at an increasing rate as the attachment point$ increases. This reflects the fact that the variability of this layer increases at an increasing rate and thus the risk capital needed (for a given insolvency level) increases at an increasing rate. The operating cost function $d($.) is assumed to increase at a decreasing rate as the attachment point $L$ increases. Consequently, the marginal cost of insurance, net of the expected loss, has a U-shape. 
Under such assumptions, the cost of insurance of a risk layer $\left[L_{1}, L_{2}\right]$, with $L_{1}<L_{2}$, is equal to $P\left(L_{2}\right)-P\left(L_{1}\right)$.

\section{Contingent credit facility}

Contingent debt is an alternative risk transfer (ART) product which enables the client to access capital after the occurrence of some specific contractually pre-defined loss, often on pre-loss financing terms. It is designed to provide immediate and less expensive capital to the client when it is most needed (e.g., after an economic loss) and/or most scarce (e.g., after a regional disaster). Contingent capital facilities can be viewed as call options on capital issued to the client. More specifically, contingent capital is a commitment by a capital provider to provide the buyer of the facility with capital on preagreed terms if he decides to exercise that right on or before the expiration of the contingent facility (Culp, 2002).

We assume that the terms of the credit are $l_{r} \%$ interest rate, chargeable upon disbursement of the loan, with a maturity of $m$ years. For the sake of simplicity, we assume that the cash flow pattern of the credit facility follows that of a zero coupon bond. ${ }^{8}$ A commitment fee of $l_{c} \%$ charged on the committed loan is paid every year for maintaining the credit line in a stand-by status. A front-end fee of $l_{f} \%$ is charged on the disbursed amount of capital. The expected present value of contingent debt, net of the expected loss of capital, for the layer of risk $[0, L]$ is thus equal to

$$
h(L)=\left[l_{f}+\left(\frac{1+l_{r}}{1+r}\right)^{m}-1\right] E \min (\tilde{l}, L)+l_{c}[L-E \min (\tilde{l}, L)],
$$

where $r$ is the country's discount rate (e.g., inflation rate), with $r<l_{r}$.

One can easily show that the function $h($.$) is increasing with L$, with $h^{\prime}(L)=\left[l_{f}+\left(\frac{1+l_{r}}{1+r}\right)^{m}-1\right][1-F(L)]+l_{c} F(L)>0$, where $F($.$) is the cumulative distribution$

function of $\tilde{l}$ and $f \equiv \partial F / \partial L$. We assume that the commitment fee $l_{c} \%$ is small enough compared to the front-end-fee and the interest rate so that $h^{\prime \prime}(L)=-\left[l_{f}+\left(\frac{1+l_{r}}{1+r}\right)^{m}-1-l_{c}\right] f(L)<0$.

We assume that the country assesses the cost of contingent debt at its expected value. This means that the country acts as a risk-neutral agent. This assumption is realistic if the country has a large tax base to spread its risk efficiently (Arrow and Lind, 1970).

\section{Reserve fund}

The country can borrow from itself and thus build financial reserves that can be used once a catastrophe occurs. The cost of reserves thus represents the discounted cost of

\footnotetext{
${ }^{8}$ Zero coupon bonds are bonds that do not pay interest during the life of the bonds. When they mature, the investor will receive one lump sum equal to the initial investment plus interest that has accrued.
} 
foregone investment in development expressed as expected rate of economic return on government investments in development projects $l_{s} \%$ (e.g., measured by the GDP growth rate) net of interest rate earned on low return by risk free government securities $(s \%)$. The present value of holding reserves net the expected loss for the layer $[0, L]$ is given by

(3) $S=\frac{l_{s}-s}{1+r} L$, with $l_{s} \geq s$.

\section{Optimization problem}

The objective of the Government is to design the least expensive ex ante risk financing strategy which covers all losses higher than $\underline{L}$ and lower than $\bar{L}$. For the sake of simplicity, each layer of risk is financed by only one financial instrument, i.e., risk sharing arrangements are not allowed within each layer of risk. ${ }^{9}$

This problem is addressed by layering the resource gap $[\underline{L}, \bar{L}]$ into an infinite number of layers and then by selecting the least expensive financing instrument (i.e., reserves, reinsurance or contingent debt) within each layer. Consider the layer of risk $[L, L+\varepsilon]$, with $\varepsilon>0$ very small. In the absence of arbitrage opportunities, the expected cost of financing this layer, net of the expected loss, is equal to

$$
\begin{array}{ll}
\frac{l_{s}-s}{1+r} \varepsilon & \text { for reserves; } \\
P(L+\varepsilon)-P(L) \cong P^{\prime}(L) \varepsilon & \text { for catastrophe insurance; } \\
h(L+\varepsilon)-h(L) \cong h^{\prime}(L) \varepsilon & \text { for contingent debt. }
\end{array}
$$

The cost-effective strategy for the layer $[L, L+\varepsilon]$ is thus the one which minimizes the marginal costs evaluated at $L$ :

$$
\min \left\{\frac{l_{s}-s}{1+r}, P^{\prime}(L), h^{\prime}(L)\right\} .
$$

\section{Efficient ex ante risk financing strategy}

Optimal ex ante risk financing strategies are analyzed by comparing the marginal of cost of risk of each financial instrument. The proposed model offers a graphical interpretation to shed analytical light on some of the key financial drivers of the optimal risk financing strategy and to provide some quantitative guidance on the financing of the resource gap.

Define $c^{\prime}$ as the minimum marginal insurance cost, i.e., $c^{\prime}=\min _{L}\left[P^{\prime}(L)\right], \underline{c}$ as the marginal cost of contingent debt with maximum loss $\bar{L}$, i.e., $\underline{c}=h^{\prime}(\bar{L})$, and $c^{\prime \prime}$ such that the marginal cost of contingent debt is equal to the marginal cost of catastrophe insurance, $h^{\prime}\left(L^{\prime \prime}\right)=c^{\prime \prime}=P^{\prime}\left(L^{\prime \prime}\right)$.

\footnotetext{
${ }^{9}$ See Gurenko and Mahul (2003) for optimal risk sharing arrangements within layers of risk.
} 
We assume that $\bar{L}$ is large enough so that $c^{\prime}>\underline{c}$. Otherwise, the contingent debt is not used as a risk financing instrument. The model includes many financial parameters that will shape the optimal financial strategy. In order to illustrate this model, we focus our discussion on the impact of a change in the marginal costs of reserve on the optimal financial strategy, with the cost of the other financial instrument being unchanged. The key role of reserves is highlighted by Caballero (2003).

Four cases are discussed and described in figures presented in the next pages.

Case 1: High cost of reserves, $S>C^{\prime \prime}$.

As illustrated in Figure 3, reserves are the least expensive financing instrument for the financing of losses $\left[\underline{L}, L_{1}\right]$. Insurance is the least expensive instrument for losses within the interval $\left[L_{1}, L^{\prime \prime}\right]$. Contingent debt is the least expensive instrument for losses $\left[L_{1}, L^{\prime \prime}\right]$. Therefore, optimal risk financing strategy, as depicted in Figure 3b, consists of building reserves to cover losses between $\underline{L}$ and $L_{1}$, buying a layer of catastrophe insurance to cover losses between $L_{1}$ and $L^{\prime \prime}$, and purchasing contingent debt to finance losses between $L^{\prime \prime}$ and $\bar{L}$.

Case 2: Medium-high cost of reserves, $c^{\prime \prime}>S>c^{\prime}$.

As shown in Figure 4, an optimal risk financing arrangement requires to build reserves to cover losses between $\underline{L}$ and $L_{1}$ and between $L_{2}$ and $L_{3}$, to buy a layer of catastrophe insurance between $L_{1}$ and $L_{2}$, and to buy contingent debt between $L_{3}$ and $\bar{L}$.

Case 3: Medium-low cost of reserves, $c^{\prime}>S>\underline{c}$.

As shown in Figure 5, catastrophe insurance becomes an expensive instrument compared to the other financial instruments, whatever the severity of the loss. The Government should build reserves between $\underline{L}$ and $L_{3}$, and buy contingent debt between $L_{3}$ and $\bar{L}$.

Case 4: Low cost of reserves, $\underline{c}>S$.

An optimal risk financing arrangement involves building reserves only (see Figure 6). Reserves are thus used as the only ex ante instrument to finance exogenous shocks, as observed in many countries (Culp 2003). However, in this particular case, this strategy is optimal because the marginal cost of internal capital is low. This may be the case in a country with a high level of liquidity with limited investment opportunities.

\section{Risk-averse country}

The assumption of country's risk-neutrality claimed by Arrow and Lind (1970) may not hold for most middle and low income countries exposed to natural disasters. Their tax base is not large enough to spread catastrophic losses among the taxpayers and their high level of indebtedness may limit their capacity to borrow.

The optimal risk financing strategy is re-examined under the assumption that the country exhibits risk aversion to natural diasaters. The cost of inter-temporal risk transfer instruments like contingent credit is thus higher than the expected cost due to the 
presence of a risk premium. ${ }^{10}$ We assume that the risk premium $\pi(L)$ associated with the contingent credit facility providing full coverage for the layer of risk $[0, L]$ increases at an increasing rate with $L$. The expected present value of contingent debt, net of the expected loss of capital, for the layer of risk $[0, L]$ becomes

$$
h(L)=\left[l_{f}+\left(\frac{1+l_{r}}{1+r}\right)^{m}-1\right] E \min (\tilde{l}, L)+l_{c}[L-E \min (\tilde{l}, L)]+\pi(L) .
$$

We also assume the marginal cost of capital of the reserves increases with $L$.

We illustrate the case where the country's risk aversion is large enough so that $h(L)$ increases at a decreasing rate for small $L$ and increases at an increasing rate for large $L$. The optimal risk financing strategy is depicted in Figure 7. The optimal strategy requires to build reserves to cover losses between $\underline{L}$ and $L_{1}$, to buy contingent debt to finance loss between $L_{1}$ and $L_{2}$, and to buy catastrophe insurance between $L_{2}$ and $\bar{L}$.

\section{Numerical example}

This discussion is illustrated with a hypothetical numerical example to further highlight how the marginal costs of the financial instruments impact the efficient risk financing strategy.

To keep this numerical example simple, the country is assumed to be risk neutral.

The cost of catastrophe insurance is assumed to be: $P(L)=0.002\left[\frac{L^{2.003}}{2.003}+25 \ln L\right]$.

The financial parameters of the contingent credit facility are: $l_{r}=5.0 \%, m=10$ years, $l_{c}=0.35 \%, l_{f}=0.5 \%$ and $r=2.5 \%$.

The financial parameters of the reserve fund are $l_{s}=5 \%$ and $s=2.5 \%$.

The catastrophic loss is assumed to follow a Gamma distribution, with parameters $\alpha=1$ and $\beta=2$. This means that the expected loss is 2 (e.g., in tens of millions dollars) and its coefficient of variation is $200 \%$.

As shown on Figure 8, the optimal risk financing strategy consists of building 25 million reserves fund, purchasing catastrophe insurance for USD30 million in excess of USD25 million and buying contingent debt of USD245 million in excess of USD55 million.

It is noteworthy that an increase in the interest rate of the contingent credit would increase the demand for catastrophe insurance. For example, if the interest rate $r$ increase by 100 basis points to $6 \%$, then the Government should increase the insurance coverage by USD10 million, thus buying a USD47 million in excess of USD 25 million catastrophe insurance (see Figure 9).

\footnotetext{
${ }^{10}$ As shown by Arrow (1965), this risk premium is proportional to the country's degree of absolute risk aversion and the variance of the macro risk, as a first approximation.
} 


\section{Conclusion}

Developing countries' fiscal position and the vulnerability of the poor are being adversely affected by the increasing frequency and severity of natural disasters. This reality calls for more than the provision of humanitarian assistance. It underpins the World Bank's work on natural disaster funding which promulgates a country risk management model largely based on corporate risk management principles, but allowing for economic and social metrics such as government fiscal profiles, GDP growth and the living conditions of the poor. This country risk management approach relies on three key requirements.

- Tangible incentives for active risk management. Post-loss financing arrangement should reward the countries pursuing active catastrophe risk management with additional fiscal resources for rehabilitation of destroyed state-owned assets. This additional financial assistance should be known in advance and be contingent on the country's mitigation efforts.

- Rapid disbursement. Despite the considerably shortened time frames required for the preparation of emergency reconstruction loans when compared to the Bank's other lending operations, emergency loans are still relatively slow to disburse. Consequently, these lending instruments are inappropriate for meeting the government's immediate and often significant liquidity needs in the aftermath of natural disasters which, if unsatisfied, can worsen the negative social and economic consequences.

- Promotion/development of private risk transfer markets. The Bank has an important role to play by bringing together government and private reinsurance and capital markets and by facilitating the development of catastrophe insurance risk markets in its client countries.

Countries need to develop appropriate ex ante risk financing strategies to supplement the traditional ex post sources of funding from government's own budget and international donors. This paper offers a country risk financing framework where the range of ex ante risk financing strategies is described. A key issue is the design of cost-effective risk financing arrangements based on the risk profile and the costs of available risk financing instruments. Using an original graphical analysis, this paper has examined costminimizing risk-financing arrangements. They are solved for every layer of risk through the comparison of the marginal cost functions of financial instruments. This approach has enabled to capture the impact of financial parameters (such as insurance premium, cost of capital and contingent debt) on the efficient risk financing structure.

The proposed model is simple enough to shed analytical light on some of the key issues to be addressed in the design of country risk financing strategies, but flexible and realistic enough to provide some quantitative guidance on the financing of the resource gap. It highlights the complementarity of the risk financing instruments for different layers of risk, based on their marginal costs. 


\section{References}

Arrow, K.J. (1965). Aspects of the Theory of Risk Bearing. Helsinki: Yrjo Jahnsson Lectures.

Arrow, K. and R. Lind (1970). Uncertainty and the Evaluation of Public Investment Decisions, American Economic Review 60(3), 364-378.

Caballero, R. 2003. "The Future of the IMF and the World Bank," American Economic Review 93(2), 31-38.

Coate, S. 1995. “Altruism, the Samaritan’s Dilemma, and Government Transfer Policy,” American Economic Review 85, 46-57.

Culp, C. 2002. “Contingent Capital and the Art of Corporate Finance,” in Alternative Risk Strategies, (Edited by M. Lane), Risk Book, pp.119-154.

Doherty, N. 2000. Integrated Risk Management. (New York: McGraw Hill).

Freeman, P., M. Keen and M. Mani. "Dealing with Increased Risk of Natural Disasters: Challenges and Options,” Washington DC: Working Paper of the International Monetary Fund, WP/03/197.

Froot, K., D. Scharfstein and J. Stein. 1993. "Risk Management: Coordinating Corporate Investment and Financing Decisions,” Journal of Finance 48, 1629-1658.

Gurenko, E.N. and R. Lester. 2004. "Rapid Onset National Disasters: The Role of Financing in effective Risk Management," World Bank Policy Research Working Paper 3278.

Gurenko, E. and O. Mahul. 2003. "Combining Insurance Contingent Debt, and SelfRetention in an Optimal Corporate Risk Financing Strategy,” World Bank Policy Research Working Paper 3167.

Hofman, D. and O. Mahul. 2006. "Insuring Public Finances Against Natural Disasters A Survey of Options and Recent Initiatives”, IMF Working Paper WP/06/199.

Kaplow, L. 1991. "Incentives and Government Relief for Risk," Journal of Risk and Uncertainty 4, 167-175.

Khater, M. and D. Kuzak. 2002. "Natural Catastrophe Loss Modeling," in Alternative Risk Strategies, (Edited by M. Lane), Risk Book, pp.271-299.

Kunreuther, H. 1996. “Mitigating Disaster Losses Through Insurance,” Journal of Risk and Uncertainty 12, 171-187.

Lewis, C. and K.C. Murdoch. 1996. "The Role of Government Contracts in Discretionary Reinsurance Markets for Natural Disasters,” Journal of Risk and Insurance 63, 567597.

Pollner, J.D. 2001. "Managing Catastrophic Disaster Risks Using Alternative Risk Financing and Pooled Insurance Structures,” World Bank Technical Paper No 495.

Priest, G. 1996. "The Government, the Market, and the Problem of Catastrophic Loss," Journal of Risk and Uncertainty 12, 219-237.

World Bank. 2003. “World Bank Annual Report”. Washington DC. 
Figure 3a. Marginal costs of risk financing instruments, with high cost of reserves $S>c^{\prime \prime}$

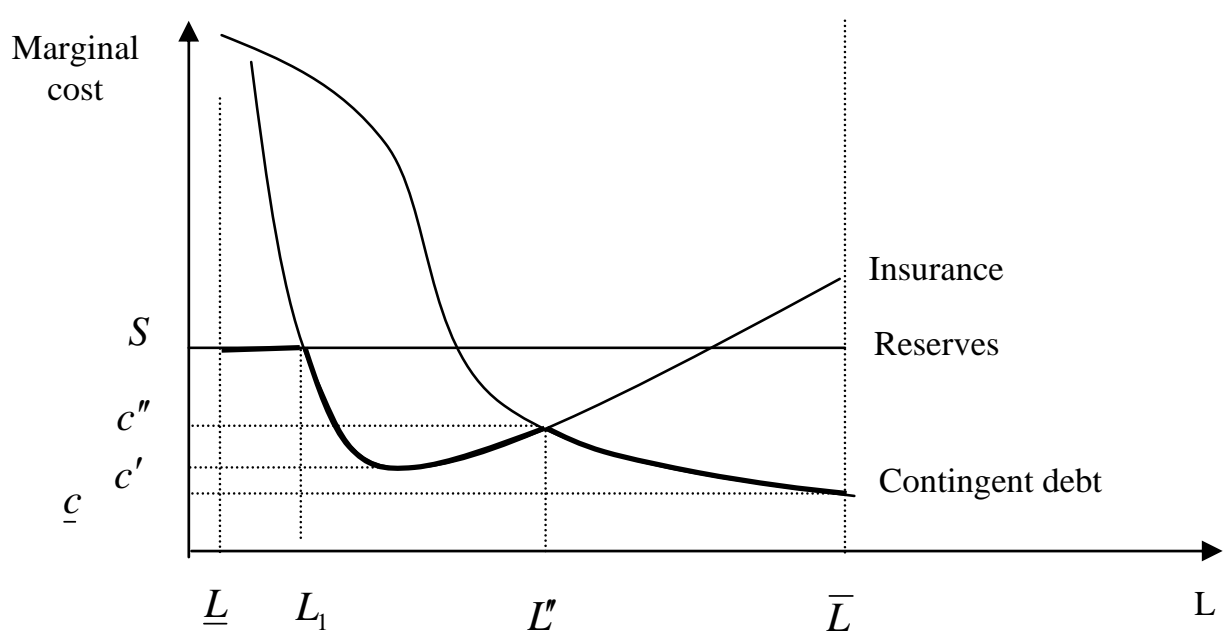

Figure 3b. Cost effective risk financing structure, with high cost of reserves $S>c^{\prime \prime}$

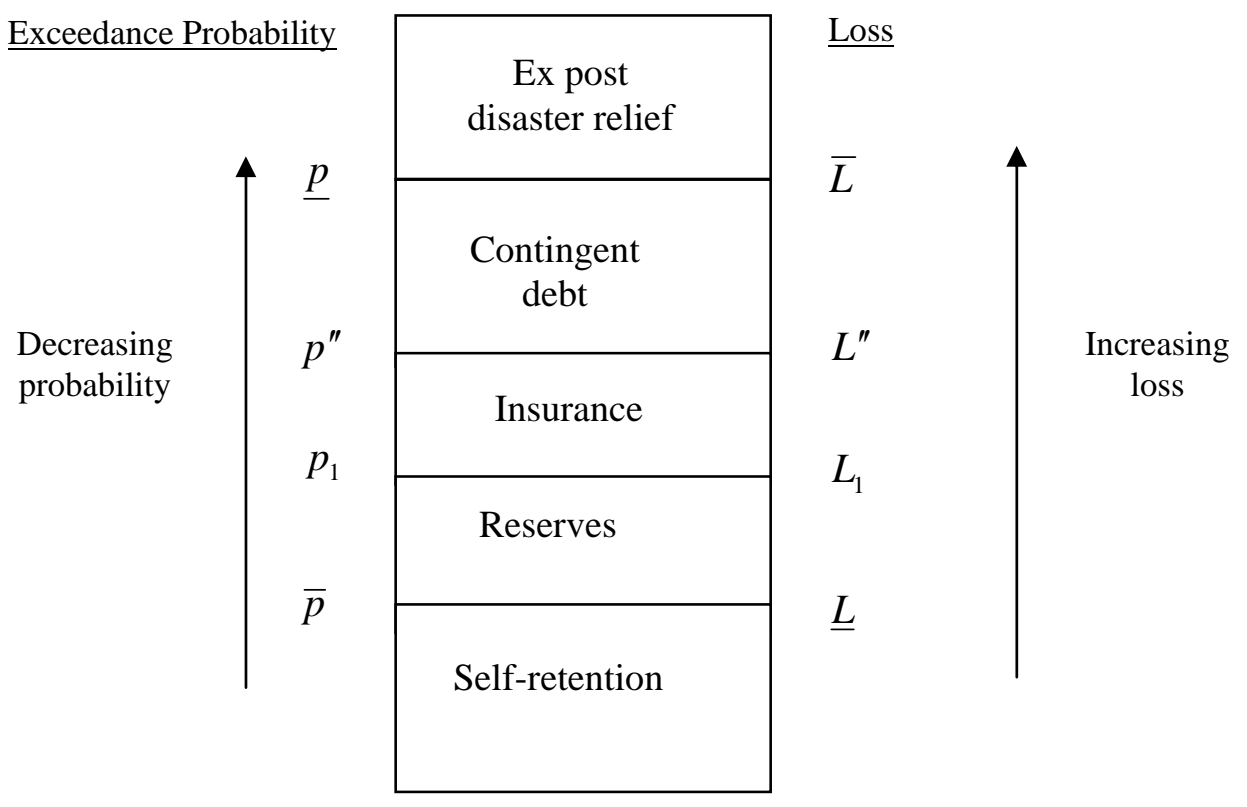


Figure 4a. Marginal costs of risk financing instruments, with medium-high cost of reserves $c^{\prime \prime}>S>c^{\prime}$

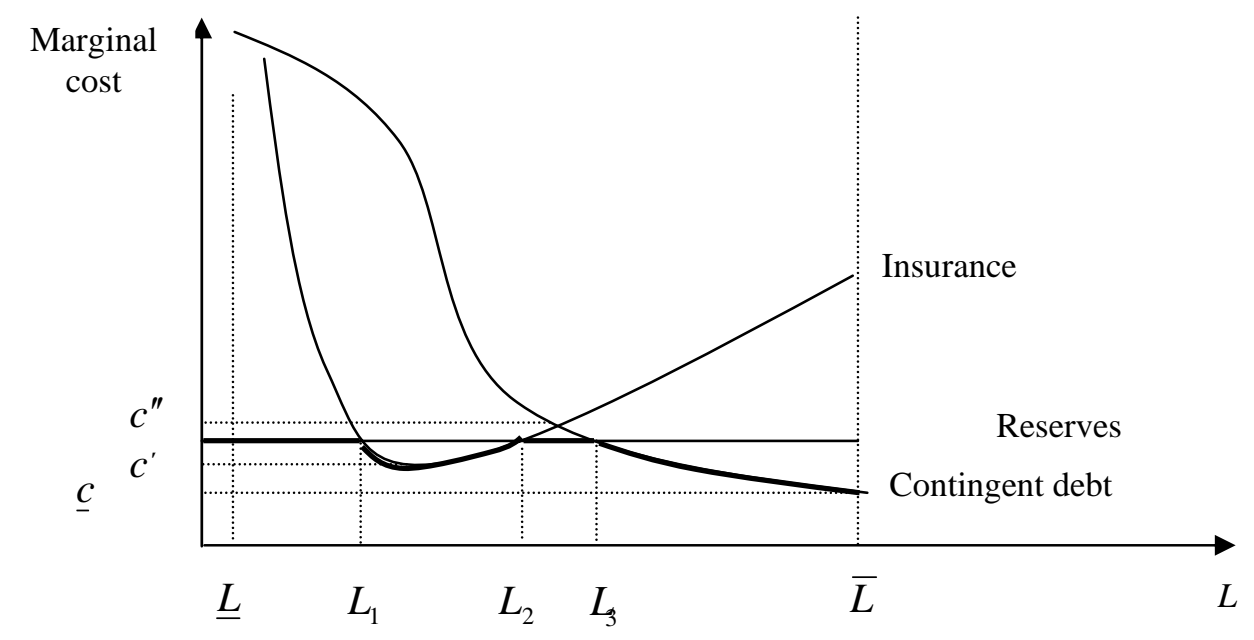

Figure 4b. Cost effective risk financing structure, with medium-high cost of reserves $c^{\prime \prime}>S>c^{\prime}$

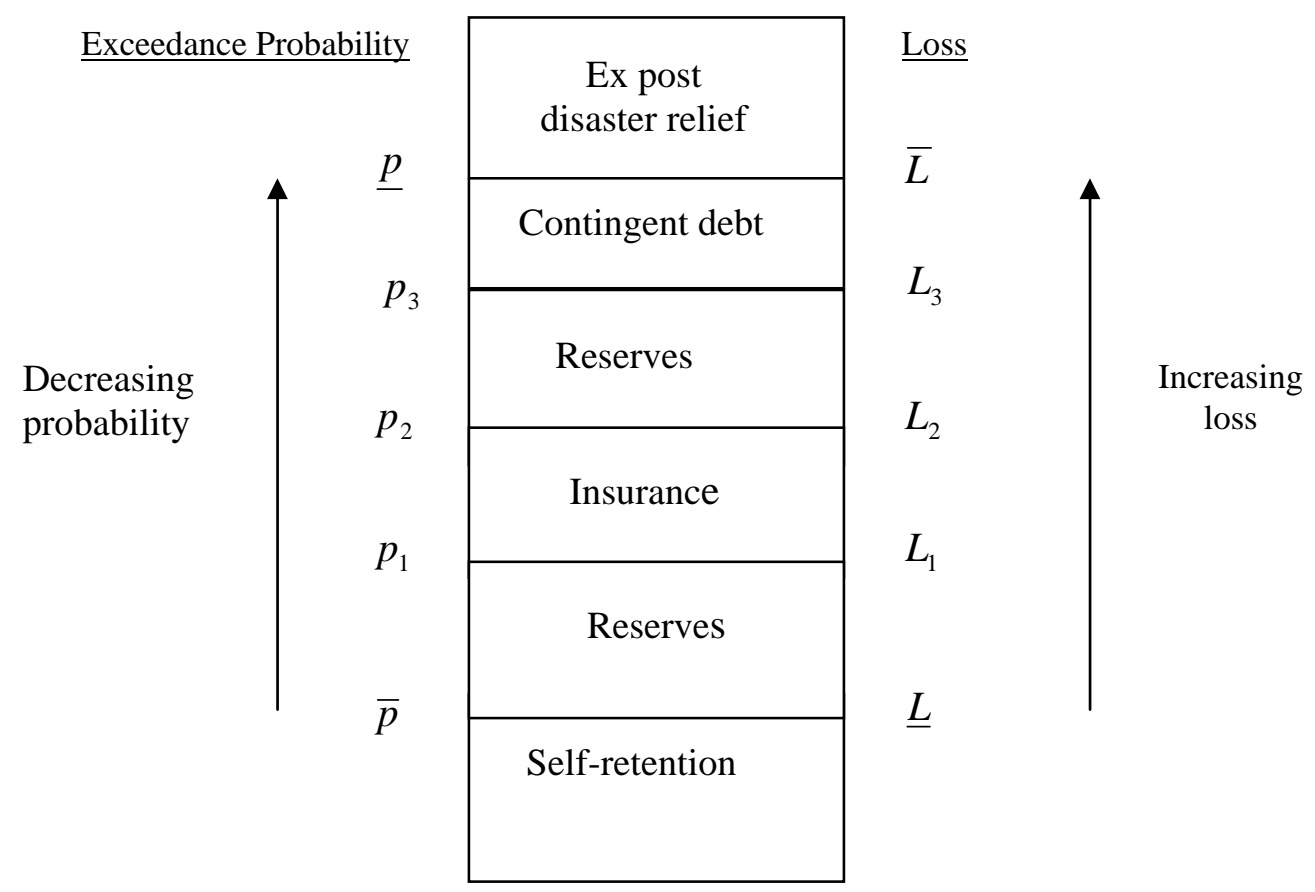


Figure 5a. Marginal costs of risk financing instruments, with medium-low cost of reserves $c^{\prime}>S>\underline{c}$

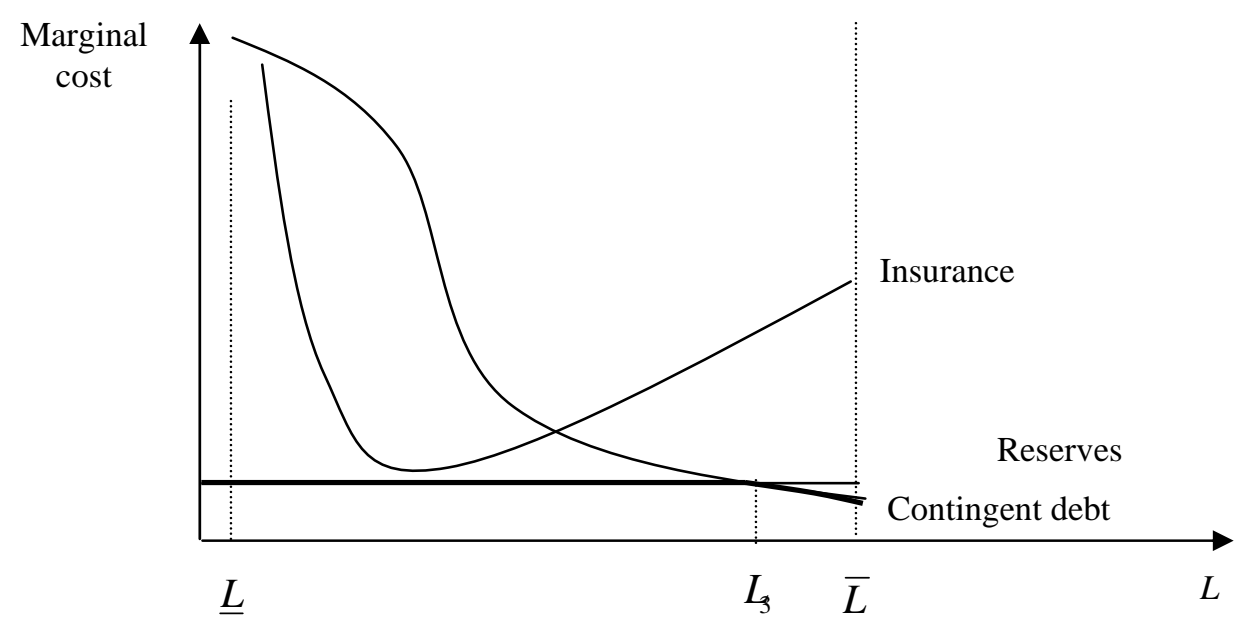

Figure 5b. Cost effective risk financing structure, with medium-low cost of reserves $c^{\prime}>S>\underline{c}$

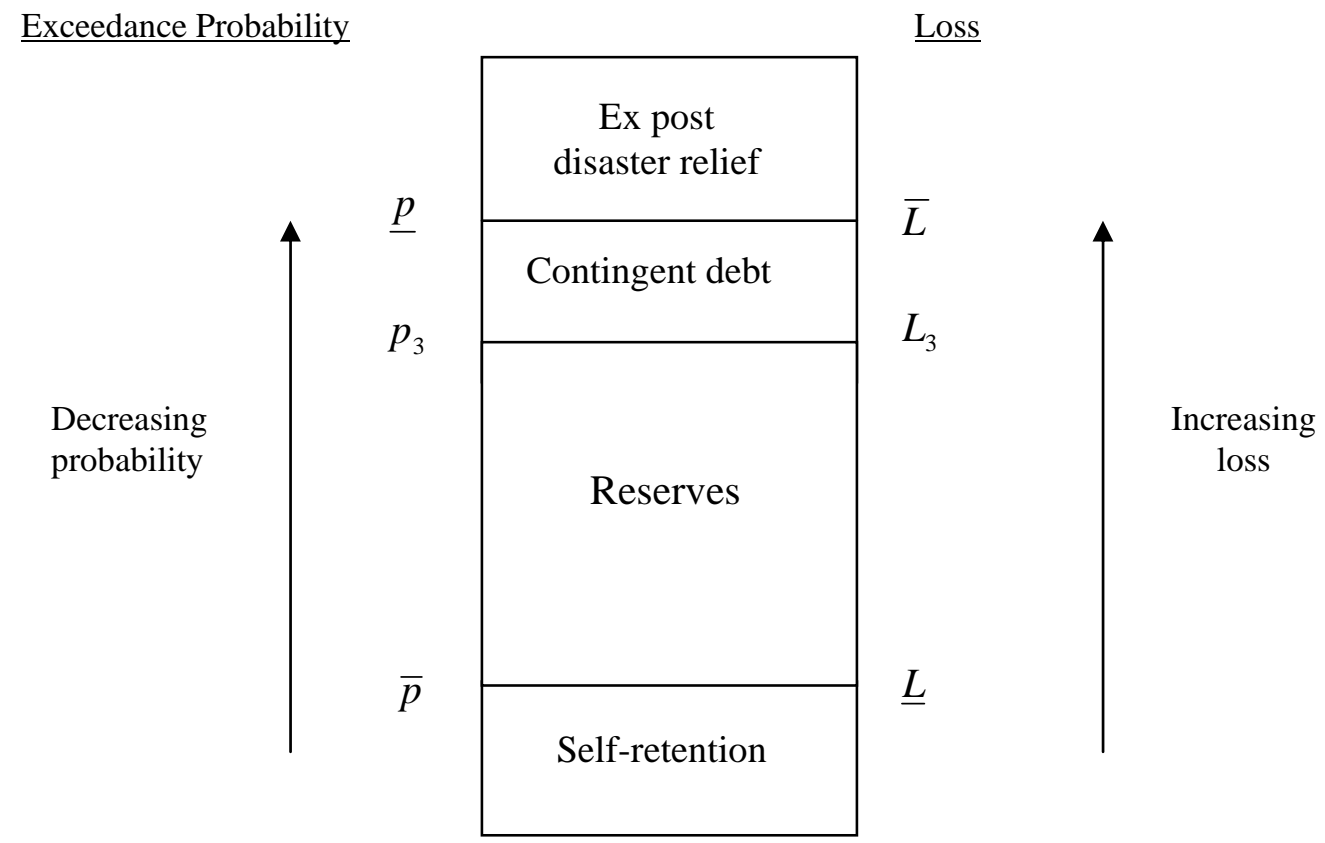


Figure 6a. Marginal costs of risk financing instruments, with low cost of reserves $\underline{c}>S$

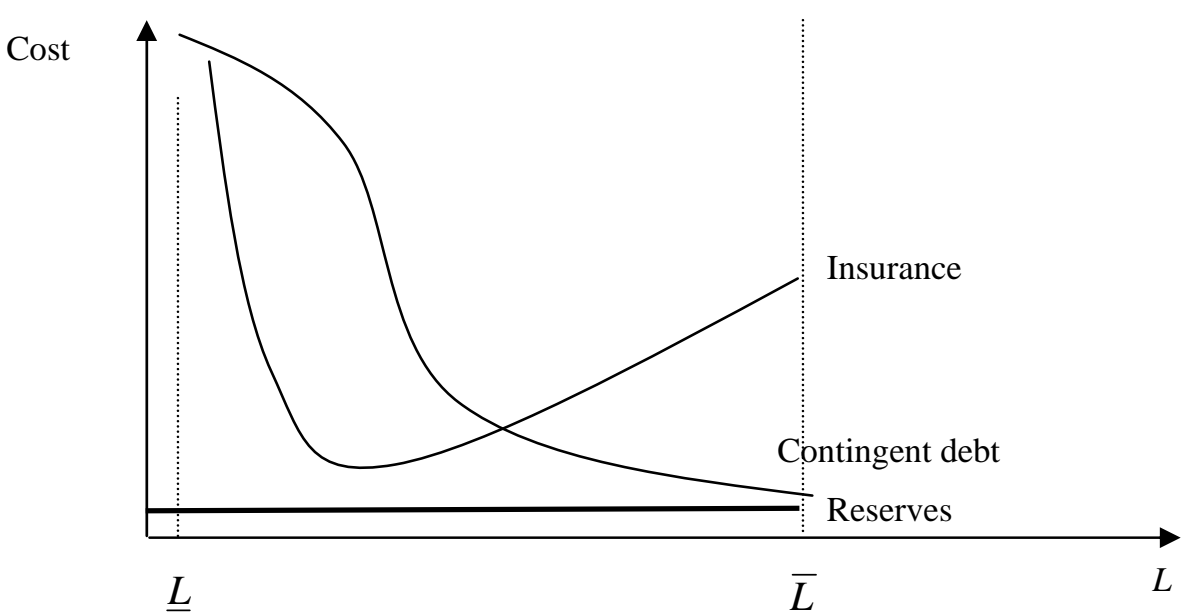

Figure 6b. Cost effective risk financing structure, with low cost of reserves $\underline{c}>S$

Probability

Loss

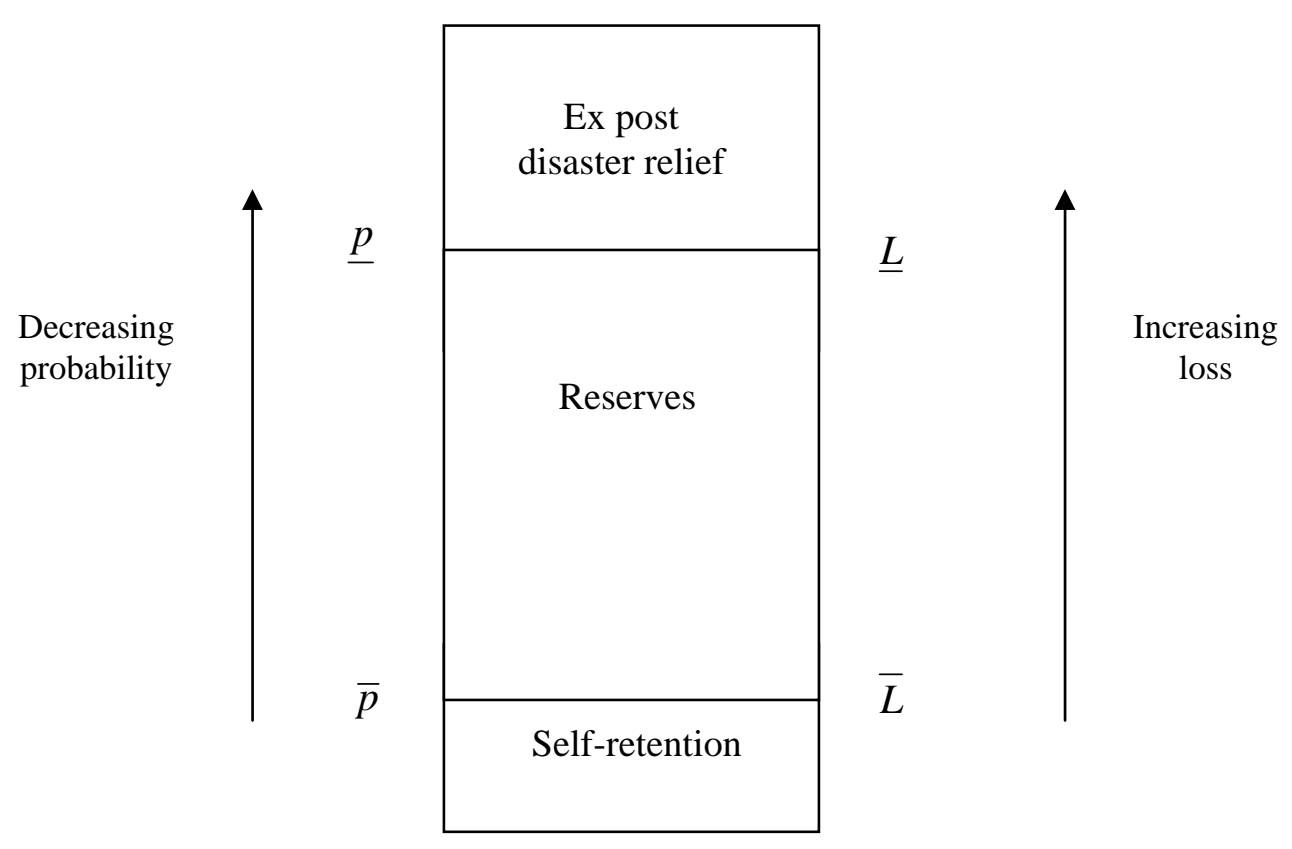


Figure 7a. Marginal costs of risk financing instruments, increasing cost of reserves

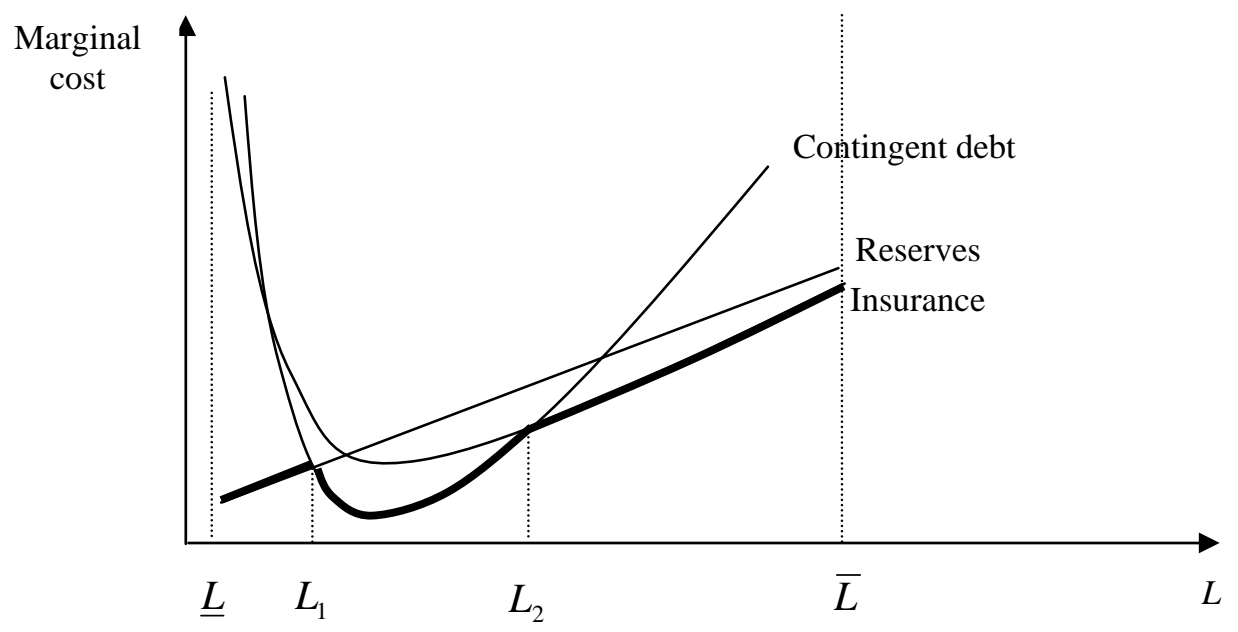

Figure 7. Cost effective risk financing structure, increasing cost of reserves

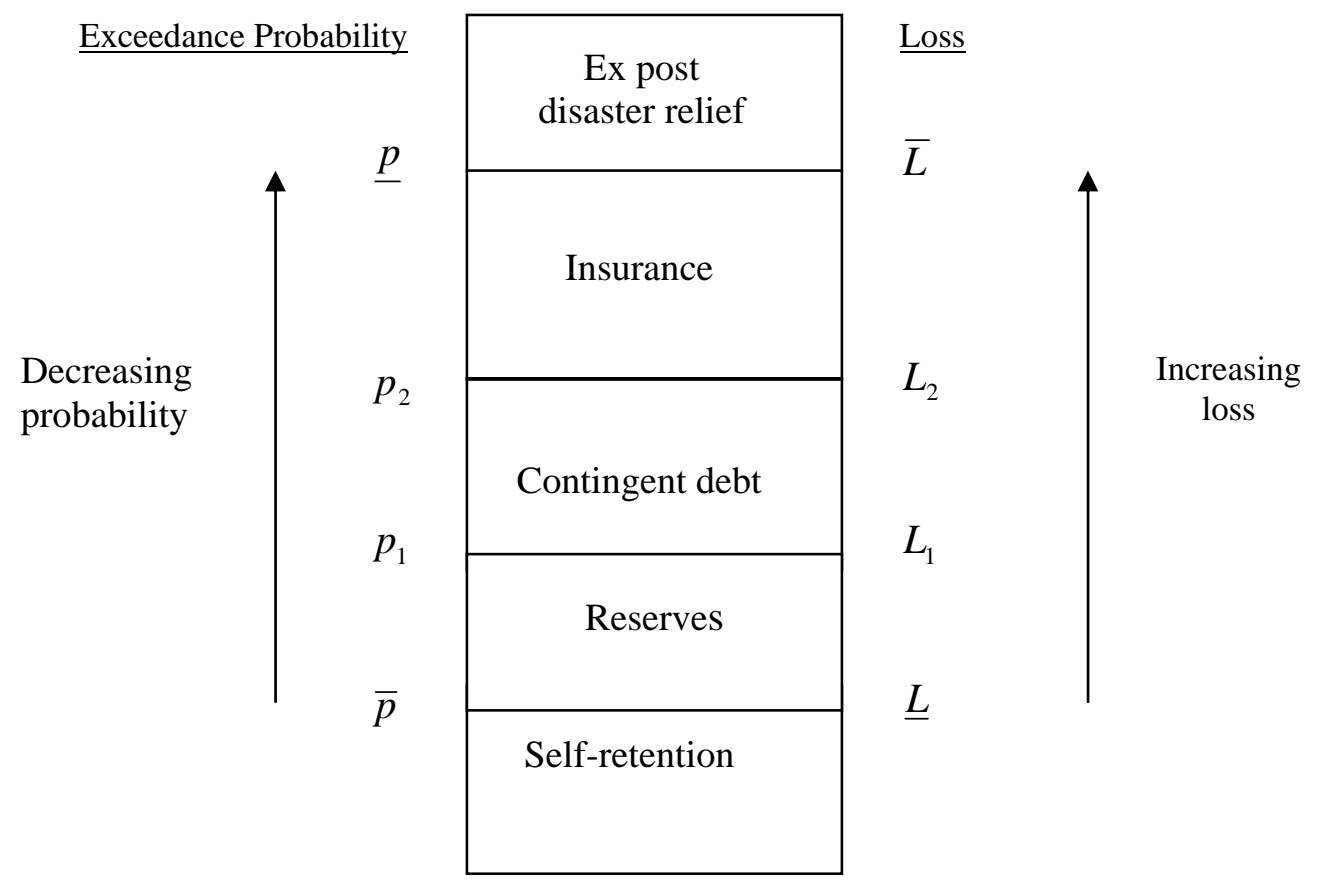


Figure 8. Numerical example: cost effective risk financing strategy (interest rate of contingent credit $=\mathbf{5 . 0} \%$ )

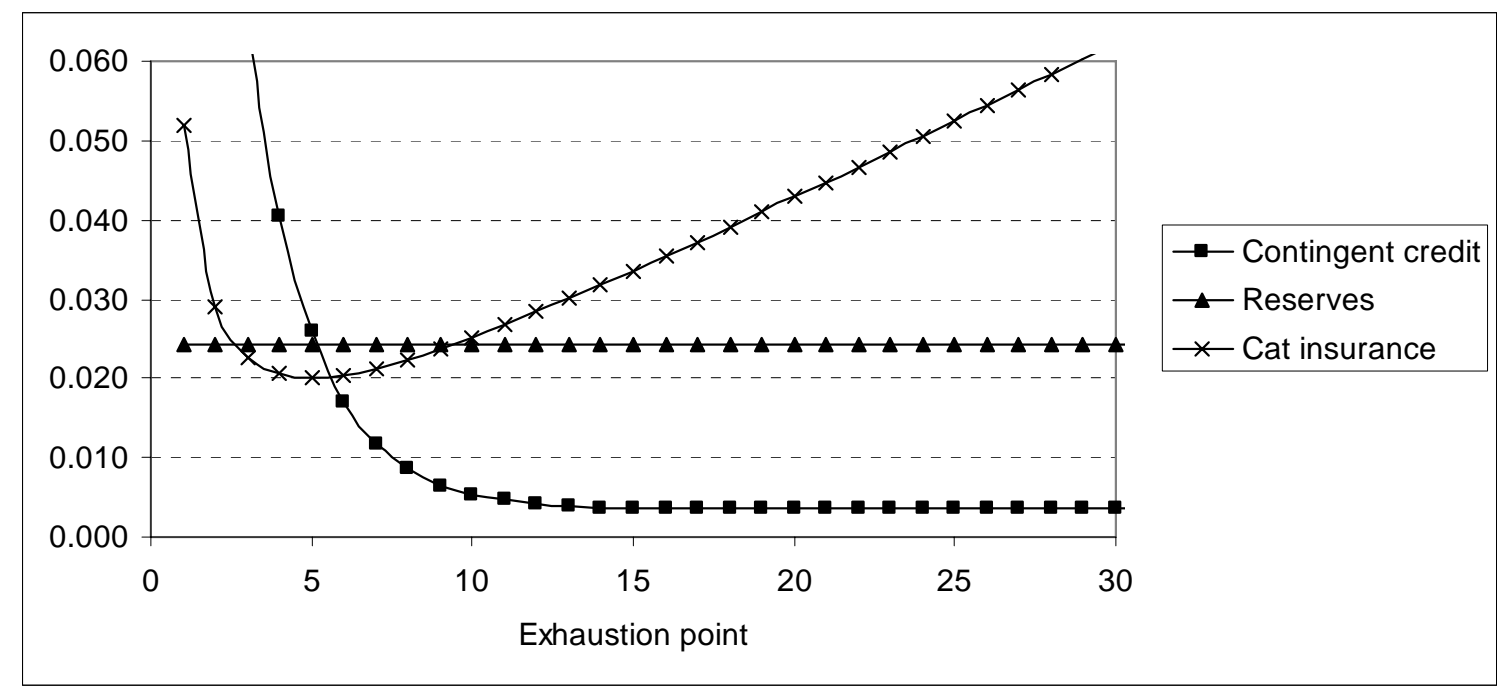

Figure 9. Numerical example: cost effective risk financing strategy (interest rate of contingent credit $=6.0 \%$ )

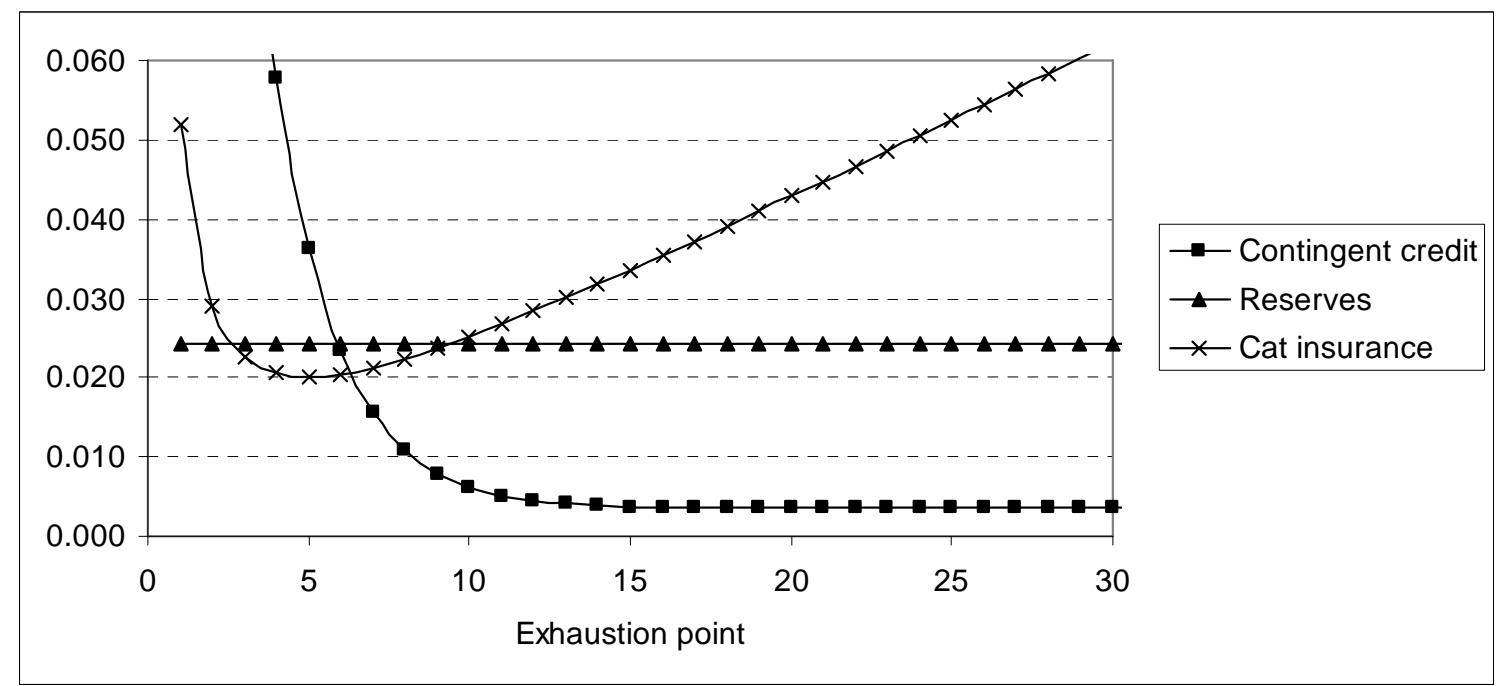

